\title{
POSITIVE REFRAMING IN SOMATOFORM AND FUNCTIONAL DISORDER - SUPPORTING THE PATIENTS IN UNDERSTANDING THE SICKNESS
}

\author{
Desislava Ruseva ${ }^{1}$, Diana Radkova ${ }^{2}$ \\ ${ }^{1}$ Department of Psychiatry and Medical Psychology, Medical University of Varna \\ ${ }^{2}$ Department of Infectious Diseases, Medical University of Varna
}

\begin{abstract}
Modern psychiatry with its current classification of diseases and symptom-oriented modern pharmacotherapy ousted the concept of classical German psychiatry genesis of diseases and replaces it with the diagnosis of physiological models of disease. Active participation of the patient in the treatment needs a full understanding of the disease. There are two psychotherapeutic techniques to achieve a new perspective and to develop a new attitude: positive reframing (4) and paradoxical intention $(1,3)$.
\end{abstract}

Keywords: positive reframing, somatoform and functional disorder, psychotherapy

The experience of successful implementation of positive reframing with patients with long drug treatment and before their contact with a psychotherapist has deployed into a guarantee for a complete psychotherapeutic process. The need of the sick person to "catch up the lost time" by psychotherapy allowed us to gain experience in using the technique "positive reframing".

Functional and somatoform disorders are perceived as somatic suffering by the patient. It's hard for them to accept that their body is healthy while they are still in suffering. They consider their functional issues for a somatic disease and cannot real-

\footnotetext{
Address for correspondence:

Desislava Ruseva, PhD

Department of Psychiatry and Medical Psychology,

Medical University of Varna,

100 Tsar Osvoboditel Blvd,

9002 Varna, Bulgaria

e-mail: Desislava.Ruseva@mu-varna.bg
}

Received: January 12, 2015

Accepted: June 11, 2015 ize how the doctor can possibly find nothing wrong with their body.

It takes time before they listen to objective reasons but not their heart (emotions) and refer to a psychiatrist or a psychotherapist. They initiate psychotherapeutic sessions still rejecting the fact that their body is fine.

Positive reframing, according to N. Peseschkian, is the shortest way to reveal the connection between symptomatic and psychological problems.

What do psychotherapists know that the patient does not?

* The good side of disease (Positum!)

* The function of symptom

They are not aware that the mind has created a new dominant (physiological symptom) to fight the psychological problems. That new dominant enables the individual to take his time and generate his psychological capacity to create a new adaptive reaction. 


\section{Example:}

A 28-year-old male with an obsessive-compulsive disorder for eight years. During this period, he had been on medical treatment, worked with a psychotherapist and tried untraditional medicine.

The symptomatology: obsessive thinking about throwing himself out of a high balcony and homosexuality. He experienced increased heart rate and suffocation which exacerbated with the fear that he was going to die because of the somatic symptoms.

Psychological problems: Feeling poor self-confidence when communicating with others; accumulating dissatisfaction, anger and rage to other people during interaction. He processed those emotions by punishing himself.

To be able to see the positive side of the symptomatology giving it time and right to exist created a range of actual experiences in the patient. During the next session, the patient shared (balance model):

* Body: "My thoughts have not vanished. In certain moments my body does not listen to me and palpation, perspiration and rapid pulse appear again. But that doesn't scare me anymore."

* Activity: "I'd forgotten that I can enjoy what I do - sports, studying, professional activities. Now I enjoy it despite the compulsions still talking my head"

* Contact: "My relationships with my parents became poor, I even moved out. I lived alone in my brother's apartment just because the contact, especially with my mother, aggravated my symptoms (still not knowing why)."

* Fantasy/Future: "I learned to visualize my symptoms as a signal (red traffic lights) for something that's not going right for me. They indicated a certain situation I had unnoticeably accumulated negative emotions to." "I started to realize that every bad thing can seem positive just by paying enough attention”, „I used to think that being sick with compulsions shows just how weak I am. At least I was sick indeed. Now I tell myself that I'm physically healthy and that my body signals help me pay attention to the actual problematic situation."

Such insights occurred after systematic psychotherapeutic contact. Most of the patients reached them after working for at least three-months with them. Their problems could also be reached in a shorter time period using positive reframing of the symptomatology by the "paradoxical intention" technique. That helps them control and take resistance off and allows for quick redirection of the therapeutic contact from the dominant Symptom to the plain Psychological problem.

\section{REFERENSES}

1. V Frankl. Psychotherapy and Existentialism. Selected Papers on Logotherapy, Simon \& Schuster, New York, 1967.

2. V Frankl. The Unheard Cry for Meaning. Psychotherapy and Humanism, Simon \& Schuster, New York, 2011.

3. MS Palazzoli. Self-Starvation: From Individual to Family Therapy in the Treatment of Anorexia Nervosa, 1974.

4. N Peseschkian. Positive Familientherapie, 1980, Fischer Verlag, Frankfurt am Main.

5. N Peseschkian. Psychosomatik und positive Psychotherapie. Springer, Berlin/ Heidelberg, 1991. 